\title{
TÓPICOS ELEGÍACOS E AS HEROIDES DE OVÍDIO: UMA ANÁLISE DA EPÍSTOLA XII DE MEDEIA A JASÃO
}

Resumo: Os tópicos ou temas elegíacos como também são chamados, são na verdade os motivos, os temas mais frequentes discutidos em um determinado texto, no caso do trabalho proposto, nas cartas elegíacas. Desse modo, o presente artigo analisa o aspecto formal da Epístola de Medeia a Jasão, dando ênfase especialmente, a presença dos tópicos elegíacos mais recorrentes na referida epístola. Para tal estudo, nos utilizamos da pesquisa bibliográfica e da abordagem qualitativa. Para isso, a pesquisa recorreu aos estudiosos da questão como Bariani (2010) Bem (2007, 2011), Cordeiro (2013), Souza (2016), entre outros autores. Concluímos, portanto, que Ovídio, na composição das lamentações amorosas, especialmente na carta de Medeia a Jasão, se utilizou dos tópicos elegíacos como mecanismo argumentativo de persuasão no jogo da conquista amorosa.

Palavras-chave: Ovídio, Herodium Epistulae, elegia romana, tópoi.

\section{ELEGIQUE TOPICS AND OVIDE HEROIDS: AN ANALYSIS OF THE EPISTLE XII FROM MEDIATION TO JASON}

\begin{abstract}
The elegiac topics or themes as they are also called, are in fact the motives, the most frequent themes discussed in a given text, in the case of the proposed work, in the elegiac letters. In this way, the present article analyzes the formal aspect of the Epistle of Medea to Jason, giving special emphasis, the presence of the most recurrent elegiac topics in that epistle. For this study, we used the bibliographic research and the qualitative approach. For this, the research appealed to scholars of the question as Bariani (2010) Bem (2007, 2011), Cordeiro (2013), Souza (2016), among other authors. We conclude, therefore, that Ovid, in the composition of amorous lamentations, especially in the letter from Medeia to Jasão, used the elegiac topics as an argumentative mechanism of persuasion in the game of amorous conquest.
\end{abstract}

Keywords: Ovid, Herodium Epistulae, Roman elegy, topoi.

1 Mestre em Letras, área de concentração em Estudos Literários, na linha de pesquisa Literatura e Recepção, pela Universidade Federal de Sergipe (DLV/PPGL/UFS). E-mail: elienefarias@hotmail.com 


\section{Considerações iniciais: sobre Ovídio e sua obra}

Segundo dados colhidos no estudo de Ana Thereza Vieira (2014), Públio Ovídio Nasão ou simplesmente Ovídio nasceu em 20 de março de 43 a. C., em Sulmona e faleceu em 17 d. C. em Tomos. O pai do poeta latino sonhava que seu filho seguisse carreira jurídica e política, e como normalmente acontecia com a alta sociedade romana no período de Augusto, Ovídio foi enviado por seu pai a Roma, juntamente com seu irmão mais velho, Lúcio, onde frequentaram as nomeadas escolas de retórica que eram comandadas pela dupla famosa da época: os mestres de retórica Aurélio Fusco e Pórcio Latrão, consoante com a pesquisa de Andréia Bariani (2010).

Jaqueline Vansan (2016) destaca que é nesse período de sua vida e nessas escolas que Ovídio começou a demonstrar seu talento pela arte. Vieira (2014, p. 28) comunga com o mesmo pensamento quando acentua que "Progredindo em sua formação, Ovídio se torna um perito na arte de debater e de persuadir; o que se mostra evidente em seus poemas amorosos", a exemplo da elegia analisada. E, por essa razão, o poeta do amor foi considerado o maior expoente dessa forma literária.

Em conformidade com o pensamento de Cecília Ugartemendía (2014), a retórica foi de suma importância para a construção das obras ovidianas. A influência dessa arte na criação literária de Ovídio é bem expressiva, como discorrido nas linhas que se seguem:

O papel da retórica na formação do jovem Ovídio foi decisivo para sua obra. De fato, os críticos concordam em afirmar que sua influência no poeta chega a ser mais importante do que em outros poetas clássicos. [...] Ovídio parece motivado pela retórica a partir do ponto de vista estético, já que é um meio para jogar com a forma, deixando entrever sua sagacidade e humor. No entanto, embora este aspecto da retórica seja muito importante no poeta de Sulmona, não é o único. A persuasão lograda por meio do artifício retórico está presente em seus escritos, e em algum deles chega a ser determinante no momento de classificá-los segundo um gênero em particular (UGARTEMENDÍA, 2014, p. 173).

Para Vansan (2016) na criação literária ovidiana, as Herodium Epistulae, é a obra que mais se destaca tendo em vista a hibridização de gêneros literários, uma vez que o autor sulmonense utilizase tanto do gênero epistolar como do gênero elegíaco para compor as epístolas da referida obra. Conforme explica Bariani (2010, p. 13-14, grifos no original), nas Heroides

Ovídio inova ao compor cartas de amor em versos. Os traços elegíacos servem agora ao propósito de cantar dores de mulheres lendárias que, nesse contexto, adquirem caráter humano e permitem conhecer seu drama no momento de tensão em que escrevem as cartas. [...] E, assim, a persona poética incorpora as amantes mitológicas, caracterizando comportamentos humanos diante da "doença" amorosa. A paixão é tema de todas as cartas e a causa de todos os males.

Essa coleção de cartas elegíacas se distingue não apenas por Ovídio resgatar fontes míticas, mas também por "aproveitar como rico plano de fundo nas narrativas que a compõem elementos da tradição literária” (VANSAN, 2016, p. 10), a exemplo da "(epistolografia, elegia erótica, lírica grega, poesia helenística) e retórica" (VANSAN, 2016, p. 148, grifo do autor). Desse modo, ainda acrescenta a autora:

Ovídio, no lugar de utilizar fontes puramente míticas, vai buscar em obras de autores já consagrados, os personagens e a matéria para escrever as Heroides. [...] figuras que antes habitavam a épica, a tragédia ou a poesia alexandrina são transportadas para o distinto mundo elegíaco. Essa característica, [...] insere o leitor em um universo literário novo, que não é moderno ou antigo, nem exclusivamente épico, trágico ou elegíaco, mas baseado na coexistência desses códigos. A abordagem intertextual do mito, dessa forma, torna-se mais um fator diferencial e enriquecedor dessa obra epistolar ovidiana. Outro elemento de estilo que exerce papel importante na constituição das epístolas das heroínas é a retórica. Vista, por vezes, como um expediente negativo [...] segundo acreditam os críticos [...] sua inserção, resultado dos exercícios escolares praticados na época de escolarização de Ovídio, [...] influenciam diretamente a estruturação das 
cartas, uma vez que, em geral, elas visam a persuadir ou a despertar a compaixão dos destinatários (VANSAN, 2016, p. 11, grifos no original).

A pesquisadora comenta que essa obra ainda se sobressai por mais dois motivos, o primeiro pelo grande diferencial das epistolas que compõem as Heroides, uma vez que o autor dos Amores cria e outorga voz a um grupo de remetentes incomum no universo literário da época. E o segundo, pela temática amorosa abordada nessas missivas, como será visto nas reflexões subsequentes (VANSAN, 2016, p. 23-24).

Como a presente pesquisa analisa a epístola de Medeia a Jasão que faz parte da obra Herodium Espistulae, é de suma importância que apresentemos a arquitetura dessa série de cartas, trabalho que passamos a executar no próximo tópico.

\section{Herodium Epistulae: a organização da obra}

$\mathrm{Na}$ carreira literária de Ovídio, as Herodium Epistulae normalmente conhecida em sua forma abreviada como Heroides, recorre a duas temáticas centrais: o amor e a mitologia grega. Segundo Mariana Carrijo Medeiros (2016) as Heroides são formadas por vinte e um poemas elegíacos, de natureza epistolar, dividida em dois grupos em que alguns estudiosos como Medeiros (2015, p. 30) define como simples e duplas.

O primeiro grupo é constituído pelos poemas de um a quinze em que contém epístolas individuais, nas quais têm-se correspondências escritas por mulheres lendárias, exceto Safo, que de acordo com ensinamentos de Gonçalves e Medeiros (2014, p. 201) é uma personagem histórica e não lendária. Nesse primeiro grupo de cartas, as heroínas míticas endereçam as missivas a seus amantes ausentes, os quais não lhes respondem.
O segundo grupo, por sua vez, vai do poema dezesseis ao vinte e um, é composto "de epístolas duplas, nas quais há a troca de mensagens entre três casais míticos: Páris e Helena, Hero e Leandro, Acôncio e Cídipe." (VANSAN, 2016, p. 20). Diferentemente do grupo anterior, essas missivas têm os heróis como remetentes e as heroínas como destinatárias, as quais respondem aos seus amantes míticos.

Essa compilação traz, majoritariamente, histórias que se originaram da mitologia grega, a exemplo da que nos propusemos a analisar neste trabalho na qual dialoga com a tragédia grega de Eurípedes em que trata do mito de Medeia e Jasão. Todavia, a epístola de número VII (de Dido a Enéias) não se enquadra nesse contexto, tendo em conta que aborda a mitologia romana (BARIANI, 2010, 14).

Ainda no que tange ao primeiro grupo, as heroínas míticas se dirigem aos seus heróis, queixando-se para que retornem, que por razões diversas, estão distantes e, posteriormente, por meio de suas ações, percebem que o amor que sentem por seus amados é exacerbado. Já a segunda coleção de missivas, "Ovídio representou não somente a mulher como escrava do amor, mas o próprio cidadão romano, que, além de se submeter ao amor, também foi representado como submisso a uma mulher" (MEDEIROS, 2016, p. 53). Como dito, nesse segundo grupo de cartas elegíacas, os remetentes são homens que inicialmente enviam cartas, revelando estarem desesperados. As mulheres, por sua vez, respondem às lamentações, às queixas dos homens, entretanto, assumem uma postura superior a seus amantes (SOUZA, 2016).

\section{A elegia erótica romana}

Segundo as considerações de Wilker Cordeiro (2013), a elegia erótica romana teve origem na literatura grega, seu vocábulo nomeava poemas 
escritos em metro chamado dístico elegíaco. Nas palavras do autor, o dístico elegíaco

consiste em dois versos, sendo um hexâmetro e um pentâmetro (mais precisamente chamado 'hexâmetro duplamente cataléctico'). O primeiro verso compõe-se de seis pés dáctilos (sílaba longa-sílaba breve-sílaba breve ou sílaba longa-sílaba longa), ao passo que o segundo verso é como o primeiro, exceto pela falta das duas breves no terceiro e sextos pés (CORDEIRO, 2013, p. 1).

Ainda de acordo com as reflexões de Cordeiro (2013), inicialmente, Os dísticos elegíacos eram cantados em ocasiões públicas. A partir da Jônia, mais precisamente nos séculos VII e VI a. C., o gênero elegíaco, propagou-se manifestandose tanto em situações públicas como particulares. $\mathrm{Na}$ elegia grega não havia uma temática específica, eram cantados feitos militares, dedicatórios, exortatórios, moralistas e polemistas.

Diante disso, pode-se inferir que esse gênero da literatura possivelmente foi muito utilizado pelos poetas, tendo em conta seu caráter atemático, já que se adequava a temas diversos. Como destaca Souza (2016, p. 44), tal metro mescla

\begin{abstract}
[...] desde os textos melancólicos ou de lamentação, principalmente fúnebres, até os textos descritivos de feitos militares e de celebrações religiosas. Desse modo, caracterizava-se como um metro bastante versátil, utilizado tanto para cantar os feitos da vida quanto os da morte. Dentre os poetas gregos desse período, Mimnermo, diferenciando-se dos demais, ocupa-se do amor.
\end{abstract}

"Nesses poemas há uma crescente preocupação com a forma. A temática amorosa era muito ligada a heróis e heroínas mitológicos. Foi justamente essa "fase" da elegia que influenciou os poetas romanos" (CORDEIRO, 2013, p. 2).

A elegia erótico-romana foi cultivada por pouco tempo, quando comparada com o trajeto histórico dos gêneros da literatura em Roma. Sua duração compreendeu os últimos anos da República Romana até os primeiros anos do Período Imperial. Os poetas latinos, mesmo com esse curto espaço de tempo, exercitaram com excelência o gênero elegíaco, a ponto de o criarem com particularidades muito distantes de sua origem grega, conforme lições de Souza (2016, p. 41).

Ainda em conformidade com o pensamento de Douglas Souza (2016) o gênero elegíaco não pode ser considerado como um gênero elevado por razões não somente formais, mas também conteudísticas. Porém, mesmo se afastando da tradição aristotélica, a elegia, segundo as pesquisas de Souza, ocupa um lugar intermediário na classificação dos gêneros, por três motivos: a) por não usar palavrões, b) por não explicitar o sexo e c) por se afastar do uso real da língua. Razões pelas quais a elegia não é um gênero elevado nem inferior, e sim, intermediário.

No que diz respeito aos aspectos formais da poesia elegíaca, vale destacar que na composição desses poemas, especialmente nos de Ovídio, há a recorrência de elementos designados de os Tópoi ou lugares-comuns. Consoante as lições de Souza (2016, p. 50) são exatamente nesses tópicos que consiste a inovação da poética ovidiana. Ainda no que concerne aos aspectos formais da elegia, Cordeiro (2013, p. 22-23) declara que

A elegia romana é, em toda sua extensão, repleta desses motivos, que muitas vezes já eram comuns nos epigramas alexandrinos. As histórias tendem a gravitar em torno de algumas situações e personagens padrões, recorrentes. Estas personagens-chave são o amante (amator), geralmente nomeado como o próprio eu-lírico, e a mulher amada (puella), que quase sempre é apresentada por um "pseudônimo". O amante é relativamente pobre e não pertence às famílias mais poderosas (ao contrário de alguns dos autores), mas é sensível e talentoso e confia na sua poesia para conquistar a amada. Ele tolera a falta de reciprocidade por parte dela, mas se abate diante da infidelidade crônica e tem forte ciúme de qualquer possível rival. 


\section{Lugares-Comuns da elegia}

Wilker Cordeiro (2013) afirma que o vocábulo tópos é definido como lugar-comum, temas ou motivos. Na elegia romana os tópicos recorrentes são: a) Diues amator (amante rico), b) Seruitium amoris (servidão amorosa), c) exclusus amator (amor excluído), d) Foedus et fides (convite à fidelidade), e) Magister amoris (professor do amor), f) Militia amoris (luta amorosa), g) Recusatio (recusa), h) Morbus amoris. Apresentamos em um quadro a seguir em que consiste cada um desses tópoi e, para isso, nos valeremos das considerações de Souza (2016, p. 50).

\begin{tabular}{|c|c|}
\hline $\begin{array}{l}\text { Diues amator } \\
\text { (Amante rico) }\end{array}$ & $\begin{array}{l}\text { Em comparação a um possível rival amoroso, } \\
\text { mais velho e mais rico, dotado de muitos } \\
\text { bens, isto é, que pode oferecer à amada muitos } \\
\text { presentes, o amans se coloca como pauper, pois } \\
\text { só pode oferecer a poesia }\end{array}$ \\
\hline $\begin{array}{l}\text { Seruitium amoris } \\
\text { (Servidão amorosa) }\end{array}$ & $\begin{array}{l}\text { o homem apaixonado, por estar fora de si, não } \\
\text { pode controlar a si próprio; torna-se um escravo } \\
\text { do amor e de sua amada (que de puella passa a ser } \\
\text { domina). Destaca-se aqui uma clara inversão na } \\
\text { hierarquia patriarcal }\end{array}$ \\
\hline $\begin{array}{l}\text { exclusus amator } \\
\text { Amor excluído }\end{array}$ & $\begin{array}{l}\text { o amans, por estar em estado de submissão, passa } \\
\text { muitas noites em claro, diante da porta da domina } \\
\text { (paraklausithyron), sentindo-se excluído. Muitas } \\
\text { vezes, a cena torna-se ridícula pois há certa } \\
\text { interação com a porta, o que, sem dúvida, remete } \\
\text { ao gênero cômico. }\end{array}$ \\
\hline $\begin{array}{c}\text { Foedus et fides } \\
\text { Convite à fidelidade }\end{array}$ & $\begin{array}{c}\text { o amans exige de sua amada fidelidade, como } \\
\text { se houvesse entre eles uma relação oficializada. } \\
\text { Normalmente, são utilizados termos jurídicos do } \\
\text { casamento para descrever um relacionamento. } \\
\text { Também são invocados os deuses, normalmente } \\
\text { matrimonias, como testemunhas desse laço de } \\
\text { fidelidade. }\end{array}$ \\
\hline $\begin{array}{l}\text { Magister amoris } \\
\text { Professor do amor }\end{array}$ & $\begin{array}{l}\text { por meio da poesia, o poeta elegíaco se julga } \\
\text { capaz de ensinar aos mais jovens acerca das } \\
\text { aventuras amorosas. Nesse sentido, a elegia } \\
\text { tanto pode ensinar o caminho para o sofrimento } \\
\text { amoroso, como também pode explicitar as } \\
\text { maneiras com que se pode amenizar esse } \\
\text { sofrimento. }\end{array}$ \\
\hline $\begin{array}{c}\text { Militia amoris } \\
\text { Luta amorosa }\end{array}$ & $\begin{array}{l}\text { a milícia do amante elegíaco é apenas a do } \\
\text { amor; o amans, quando consegue sua realização } \\
\text { amorosa, pode ser considerado um general } \\
\text { triunfante. Tal tópos se contrapõe à cultura } \\
\text { bélica, que não deixa de estar ligada aos gêneros } \\
\text { elevados. }\end{array}$ \\
\hline $\begin{array}{l}\text { Recusatio } \\
\text { Recusa }\end{array}$ & $\begin{array}{l}\text { recusa-se a poesia de natureza elevada; o talento } \\
\text { do poeta se volta para a poesia de amor. }\end{array}$ \\
\hline
\end{tabular}




\section{Morbus amoris \\ Amor como doença \\ está associado ao tratamento dado ao amor, na \\ Antiguidade, como uma doença da alma. O \\ amator encontra-se desequilibrado, fora de sua \\ ratio. É a contraposição direta do uir grauis}

Como visto, as elegias romanas em sua composição, são repletas desses lugares-comuns. Desse modo, este estudo investigará os tópicos elegíacos mais frequentes na epístola de Medeia a Jasão, o que configura o objetivo central desta pesquisa. Todavia, antes de adentrarmos nessa abordagem, necessário se faz que conheçamos o mito de Medeia e Jasão.

\section{Um pouco sobre o mito de Medeia e Jasão}

Medeia, filha do rei Eetes, se apaixonou por Jasão, quando este desembarcou em seu reino com o intuito de conquistar o velocino de ouro. Esse amor a fez cometer atitudes terríveis como trair seu próprio pai e a pátria, além de matar seu irmão em favor da paixão por Jasão. Sabendo que Medeia era especialista em feitiçaria, Jasão a suplica que o ajude em cada uma das fases da conquista do velocino lhe prometendo diante dos deuses casamento e fidelidade eternos (BARIANI, 2010).

Ao conseguir matar o dragão (guardador do velocino), Jasão foge de Cólquida com Medeia e com velocino e para que seu pai pare de perseguilos, ela mesma mata e esquarteja seu irmão, lançando partes do corpo dele pelo caminho como uma forma de retardar a perseguição paterna. Quando chegaram no destino, Corinto, onde governava o rei Creonte, Jasão abandona a feiticeira para se casar com Creusa, filha do rei Creonte, com o propósito de recuperar o trono perdido em Iolco. Revoltada com a situação, e sem pátria, sem família e sem amigos, Medeia decide se vingar de todos que causaram seu sofrimento, principalmente de Jasão. Para Creusa, Medeia oferece um vestido envenenado que ao vesti-lo é tomada por chamas, Creonte, ao tentar salvar a filha, também acaba morrendo queimado (BARIANI, 2010).

Por fim, Medeia se vinga de Jasão cometendo a pior das vinganças ao matar os seus próprios filhos para deixar Jasão sem nada. "Na versão euripiana, Medeia, após o assassinato, foge de Corinto numa carruagem alada, levando consigo os corpos dos filhos, para oferecê-los ao reino de Hades" (BARIANI, 2010, p. 17). Porém, é interessante destacar que a Medeia apresentada por Ovídio nas Heroides é completamente diferente da Medeia de Eurípides que é uma mulher vingativa, revoltada e traiçoeira. $\mathrm{Na}$ interpretação ovidiana ela é uma mulher que se humilha, se lamenta e se subordina características comuns do eu-lírico nos poemas elegíacos.

Um dos tópicos mais frequentes, e por que não dizer um dos temas mais corriqueiros na lamentação amorosa, é o diues amator (amante rico). Segundo as palavras de Souza (2016, p. 50) este tópico diz respeito "a um possível rival amoroso, mais velho e mais rico, dotado de muitos bens, isto é, que pode oferecer à amada muitos presentes, o amans se coloca como pauper, pois só pode oferecer a poesia".

Cordeiro (2013) chamou o dines amator de situação-padrão no gênero elegíaco, já que há a situação de um triângulo amoroso que é formado pelo amante (amator), normalmente designado como o eu-elegíaco, a mulher amada (puella) e um rival. Este, como já destacado acima, é mais velho e possui riquezas o que faz com que a puella se encante. Já o amator não possui bens, “[...] mas 
é sensível e talentoso e confia na sua poesia para conquistar a amada" (CORDEIRO, 2013, p. 22).

O "[..] diues amator pode oferecer bens materiais, mas que o pobre tem somente um outro tipo de bem a oferecer - sua fidelidade (BEM, 2007, p. 208). Nesse sentido, o amante só tem como bens e condições de eternizar o nome da amada por meio da poesia. Essa imortalidade literária é uma característica fundamental da elegia.

\section{Tópicos elegíacos no corpus analisado}

Na epístola XII de Medeia a Jasão, temos por exemplo, a recorrência ao tópico diues amator, como pode ser evidenciado nas linhas 23 a 28 da página 153 da dissertação de mestrado de Souza (2016) e nas linhas 199 a 206 das páginas 156-157 da mesma pesquisa:

Forçado a direcionar o inexperiente navio para a Cólquida/Entraste nos felizes reinos de minha pátria. /Lá, eu, Medeia, fui o que tua nova esposa é aqui; /Tanto quanto o pai dela, o meu pai era rico; /Este possui Éfera entre dois mares, aquele até a gelada Cítia, Domina tudo que se estende à esquerda do Ponto (SOUZA, 2016, p. 153, L 23-28).

Perguntas onde está o dote? Naquele campo calculamos/Que devia ser arado por ti para levares o velocino. /Aquele carneiro dificultoso e notável pelo velo áureo. /É meu dote, o qual, se te pedisse "Devolve", recusarias. /Meu dote é tua salvação, meu dote é a juventude grega. / Vai agora, perverso, e compara essa tua riqueza de Sísifo. /Que vivas, que tenhas a esposa e o sogro poderosos! / Mesmo isto, se podes ser ingrato, deves a mim (SOUZA, 2016, p. 156-157, L 199-206).

Nos dois trechos, nota-se o dines amator quando faz referência ao dinheiro, o primeiro trecho está logo no início da elegia, neste, Medeia narra sobre a gênese de seu relacionamento com Jasão, comparando os bens de seu pai com as do pai de Creúsa. Ovídio, segundo as reflexões de Cordeiro (2013), utiliza-se do raciocínio de riqueza como uma estratégia de persuasão no momento da conquista, e Medeia, ao escrever a carta se queixa de que Jasão procura Creúsa em razão de seus bens.
No segundo trecho, Medeia mais uma vez compara os bens de Creúsa aos feitos que realizou por amor a Jasão, fazendo com que se intensifique ainda mais à recorrência ao tópico do diues amator.

Outro tópico presente na epístola em abordagem é o argumento seruitium amoris (servidão amorosa), que conforme Souza (2016, p. 50) “o homem apaixonado, por estar fora de si, não pode controlar a si próprio; torna-se um escravo do amor e de sua amada (que de puella passa a ser domina). Destaca-se aqui uma clara inversão na hierarquia patriarcal. $\mathrm{Na}$ elegia amorosa, as referências a este tema podem ser vistas nas linhas 133-136, na página 155), e nas linhas 185-186. Todas as páginas apontadas integram a pesquisa de Souza (2016) como visto abaixo:

Ousaste (oh, as palavras faltam a uma dor justa!), /Ousaste dizer "retira-te da casa de Éson!” Ordenada, deixei a casa acompanhada pelos dois filhos, E, por teu amor, aquele que sempre me segue (SOUZA, 2016, p. 155, L133-136).

Sou tão suplicante contigo quanto tu foste, muitas vezes, comigo / $\mathrm{E}$ não hesito em prostrar-me a teus pés (SOUZA, 2016, p. 156, L185-186).

No tópico do seruitium amoris, percebemos que há uma servidão, uma entrega total em favor do amor, é o que pode ser visto no relato acima em que Medeia declara que sua vida foi dedicada a Jasão. Esse é também o pensamento de Bem (2011, p. 88), quando afirma que "a vida do poeta-amante é totalmente dedicada ao amor, que, por sua vez, incita a composição de versos elegíacos". Além de Medeia se mostrar escrava do amor, ela demonstra também, obediência e submissão a Jasão. O seruitium amoris, é entendido pelos elegíacos como um requisito para se obter êxito no amor.

Podemos destacar ainda na carta elegíaca de Medeia o tópico militia amoris (luta amorosa), "a milícia do amante elegíaco é apenas a do amor; $\mathrm{o}$ amans, quando consegue sua realização amorosa, pode ser considerado um general triunfante. Tal 
tópos se contrapõe à cultura bélica, que não deixa de estar ligada aos gêneros elevados" SOUZA, 2016, p. 50). Para este tópico, temos toda a epístola como exemplo, haja vista que todo o discurso de Medeia na carta é caracterizado como uma luta amorosa.

$\mathrm{Na}$ visão de Wilker Cordeiro (2013, p. 4546), o tema militia amoris é na verdade toda "a história da jovem que auxilia seu amado, de forma decisiva, a vencer batalhas e cumprir um objetivo militar (capturar e trazer o velo de ouro) pode ser caracterizada como exemplo do topos da militia amoris". Um exemplo desse lugar-comum na elegia estudada pode ser visto no trecho a seguir:

Eu mesma, que agora para ti, por fim, me tornei bárbara /Agora sou pobre para ti, agora te pareço nociva, /Conduzi os olhos flamejantes ao sono induzido/ $\mathrm{E}$ te dei, em segurança, o velocino para que levasses embora. / Meu pai foi traído, abandonei o rei e a pátria; / A melhor irmã foi abandonada com a mãe querida, / Minha virgindade tornou-se a presa de um ladrão estrangeiro, / Suportei tudo, em qualquer exílio que fosse. /Mas, irmão, fugindo, não te deixei sem mim, [...] (SOUZA, 2016, p. 155, L105-113).

No trecho acima, vemos que Medeia recorda toda milícia que realizou em benefício do amor de Jasão. Nota-se que a personagem mítica narra suas ações só que dessa vez ela relata diferente já que frisa os sacrifícios que teve de fazer para poder viver ao lado do amado. "Ao assumir o compromisso de ajudar Jasão, Medeia age como um soldado ao se alistar no exército. É como se ela passasse a ser mais um dos Argonautas, inclusive acompanhando as ações in loco" (CORDEIRO, 2013, p. 45-46).

Por fim, temos ainda na carta de Medeia o tópico Morbus amoris (amor como doença), que consoante as reflexões de Souza (2016, p. 50) “está associado ao tratamento dado ao amor, na Antiguidade, como uma doença da alma. O amator encontra-se desequilibrado, fora de sua ratio. É a contraposição direta do uir grauis", como visto abaixo:

\begin{abstract}
Afasta-te triste. Sigo-te, acompanhando com úmidos olhos, / E com murmúrio tênue, a língua disse: 'adeus'. Logo que toquei o leito posto no quarto, gravemente ferida, / Quão atormentada foi a noite que transcorreu para mim com muitas lágrimas; [...] (SOUZA, 2016, p. 154, L55-58, grifo do autor).
\end{abstract}

Ao descrever a força de seu amor por Jasão, Medeia lança mão do argumento Morbus amoris. Segundo os ensinamentos de Cordeiro (2013) esse é um dos tópicos mais marcantes e característicos da elegia. No trecho acima, a feiticeira relata que sua alma está ferida por duas razões: pela partida de seu amado e pelo amor que sente por ele.

\section{Considerações finais}

O presente artigo teve como objetivo analisar os recursos retóricos que participam da disposição das partes constitutivas da Epístola XII de Medeia a Jasão, especialmente os lugares argumentativos (topor) que integram esta obra a fim de compreender como esses elementos contribuem para sua construção. Para demonstrar e exemplificar o uso desses temas elegíacos foram utilizados trechos da carta analisada. A pesquisa demonstrou que Medeia, por meio de sua conduta, expôs traços comuns de uma amante elegíaca, ao se lamentar por ter sido abandonada mesmo tendo se entregado totalmente ao amor de Jasão, ao sofrer com insônias por causa de sua paixão e ao suplicar que Jasão mantenha suas promessas.

Diante da abordagem realizada acima, concluímos, portanto, que Ovídio, na composição das lamentações amorosas, especialmente na carta de Medeia a Jasão, se utilizou dos tópicos elegíacos como ferramenta de persuasão no jogo da conquista. $\mathrm{Na}$ carta estudada, por exemplo, vimos que o poeta lançou mão dos tópicos diues amator, militia amoris, seruitium amoris e do Morbus amoris cuja finalidade precípua como dito, foi a de favorecer no jogo da conquista amorosa. 


\section{Referências}

BARIANI, Andréia. O mito de Medeia nas Heroides de Ovídio: Epístola XII - de Medeia a Jasão. 2010, 46 f. Monografia (Bacharel em Letras) - Faculdade de Ciências e Letras, Araraquara, SP, 2010. Disponível em: <https://repositorio.unesp. br/bitstream/handle/11449/118209/bariani_a_ tcc_arafcl.pdf;sequence=1>. Acesso em: $15 \mathrm{fev}$. 2019.

BEM, Lucy Ana de. O Amor e a guerra no Livro I d'Os Amores de Ovídio. 2007, 256 f. Dissertação (Mestrado em Letras Clássicas). Universidade Estadual de Campinas, Instituto de Estudos da Linguagem, Campinas. Disponível em: $\quad<$ http://repositorio.unicamp.br/handle/ REPOSIP/269179>. Acesso em: 26 de jan. 2020

Metapoesia e confluência genérica nos Amores de Ovídio. 2011, 391 f. Tese. (Doutorado em Linguística - Letras Clássicas). Universidade Estadual de Campinas, Instituto de Estudos da Linguagem, Campinas. Disponível em: <http://repositorio.unicamp.br/handle/ REPOSIP/271128>. Acesso em: 26 de jan. 2020.

CORDEIRO, wilker Pinheiro. Tópoi Elegíacos nas Heroides de Ovídio. 2013, 137 f. Dissertação (Mestrado em Estudos Literários). Universidade Federal de Minas Gerais, Faculdade de Letras, Belo Horizonte. Disponível em: <http://www. bibliotecadigital.ufmg.br/dspace/bitstream/ handle/1843/ECAP-95DJ62/disserta_o_wilker_ vers_o_final.pdf? sequence $=>$. Acesso em 08 jan. 2019.

GONÇALVES, Ana Teresa Marques; MEDEIROS, Mariana Carrijo. Amor e Alusão à morte: um estudo acerca das representações das heroínas de ovídio. Goiás. Revista brasileira de estudos Clássicos. v, 27, n, 1, p. 197-221. 2014. Disponível em: <https://revista.classica.org.br/classica/ article/view/340/280>. Acesso em: 27 dez. 2018.

MEDEIROS, Mariana Carrijo. Entre a ausência e o desejo: considerações acerca das representações das relações amorosas romanas em epistulae heroidum de ovídio (i a.c./ i d.c.). 2015, 173 f. Dissertação
(Mestrado em História) Universidade Federal de Goiás, Faculdade de História, Goiás. Disponível em: <https://pos.historia.ufg.br/up/113/o/ D2015-18.pdf>. Acesso em: 24 dez. 2018.

Entre o cultural e o político: as Epistulae Heroidum, de Ovídio, à luz dos estudos de gênero (I a.C.-I d.C.). Goiás. Romanitas - Revista de Estudos Grecolatinos. n, 8, p. 51-69. 2016. Diponível em: <http://periodicos.ufes.br/romanitas/issue/ view/738/showToc>. Acesso em: 24 dez. 2018.

SOUZA, Douglas Gonçalves de. Lamentatio e relações intertextuais nas Heroidvm e Epistvlae de Ovídio. 2016, 157 f. Dissertação (Mestrado em Letras Clássicas) Universidade Federal do Rio de Janeiro, Faculdade de Letras, Rio de Janeiro, 2016. Disponível em: < http://www. posclassicas.letras.ufrj.br/images/Cursos/Td/ dissertacoes/2016/Vers\%C3\%A3o_Completa_ da_Disserta\%C3\%A7\%C3\%A3o_-_Douglas_ Gon\%C3\%A7alves_-_UFRJ_2016.pdf >. Acesso em: 23 dez. 2018.

VIEIRA, Ana Thereza Basílio. A contestação de Ovídio aos princípios morais de augusto nas elegias dos amores. Porto Alegre. ORGANON-Revista do Instituto de Letras da UFRGS. v, 29, n. 56, p. 27-41. Disponível em: <https://seer.ufrgs.br/organon/ article/view/43995>. Acesso em: 27 dez. 2018.

UGARTEMENDÍA, Cecília M. Ars oratoria e ars amatoria em Heroides XIV. Juíz de Fora. RONAI: Revista de Estudos Clássicos e Tadutórios. v. 2, n. 2, p. 173-189. 2014. Disponível em: < https://ronai. ufjf.emnuvens.com.br/ronai/article/view/23> Acesso em: 23 dez. 2018.

VANSAN, Jaqueline. Poética e Retórica nas Heroides de Ovídio: uma análise da Epistola I “de Penélope a Ulisses". 2016, 168 f. Dissertação (Mestrado em Estudos Literários) Universidade Estadual Paulista "Júlio de Mesquita Filho", Faculdade de Ciências e Letras, Araraquara, 2016. Disponível em: <https://repositorio.unesp.br/ bitstream/handle/11449/139555/vansan_j_me_ arafcl.pdf? sequence $=5 \&$ isAllowed $=\mathrm{y}>$. Acesso em: 23 dez. 2018.

Submissão: maio de 2020. Aceite: outubro de 2020. 